\title{
Environmental remediation of nuclear legacy sites in the Russian Northwest: regulatory approach
}

\author{
N. K. Shandala ${ }^{1}$, V. A. Seregin ${ }^{1}$, M. K. Sneve ${ }^{2}$, S. M. Kiselev ${ }^{1}$, \\ A. S. Kosnikov ${ }^{3} \&$ G. M. Smith ${ }^{4}$ \\ ${ }^{1}$ Burnasyan Federal Medical Biophysical Centre, Russia \\ ${ }^{2}$ Norwegian Radiation Protection Authority, Norway \\ ${ }^{3}$ SevRAO Facility-1, Russia \\ ${ }^{4}$ GMS Abingdon Ltd, UK
}

\begin{abstract}
Remediation of the sites for temporary storage (STS) of the Spent Nuclear Fuel (SNF) and Radioactive Waste (RW) is one of the most important challenges for the Russian Northwest region. The prime task is to develop radiation environmental regulations on justification of radiation safety assurance during remedial operations at the STS. According to legislative and normative acts of the Russian Federation regulating management of radioactively contaminated territories after identification of the site contamination level at the radiation facility, one of three decisions can be made: conservation of the site; renovation of the site and buildings (brown lawn); unlimited use of the site (greenfield). The criteria and regulations for the SNF and RW STS facilities and site have been developed, which are suitable for each remediation option. At the same time, the environmental models have been taken into account; reference levels have been developed expressed in radiation parameter units, which could be measured during radiation control and monitoring: surface beta and alpha contamination of the STS buildings, gamma dose rate, radionuclide specific activity in soil, annul activity concentration of ground water, radionuclide contents in hydrobionts.
\end{abstract}

Keywords: remediation, sites for temporary storage, spent nuclear fuel, radioactive waste. 


\section{Introduction}

Two technical bases of the Northern Fleet were created in the Russian Northwest in the 1960s at Andreeva Bay in the Kola Peninsula and Gremikha village on the coast of the Barents Sea. They maintained nuclear submarines, performing receipt and storage of radioactive waste $(\mathrm{RW})$ and spent nuclear fuel (SNF). No further waste was received after 1985 and the technical bases have since been recategorized as sites of temporary storage (STS).

Remediation of sites and facilities of the STS of SNF and RW in Andreeva bay and Gremikha village on the Kola Peninsula is one of regulatory functions of the Federal medical-biological agency (FMBA of Russia). The work has involved the Russian Federation Burnasyan Federal Medical Biophysical Centre, which is technical support organization of the FMBA of Russia. In thus work took part the Norwegian Radiation Protection Authority (NRPA) in frame of the Norwegian government's Plan of Action to improve radiation and nuclear safety in northwest Russia.

Main tasks within the FMBA - NRPA cooperation consist of:

- Independent detailed analysis of the radiation situation at and near the STSs.

- Radiological threat assessment to determine priority issues for regulatory attention.

- Radiological control and monitoring of the environmental conditions.

- Development of a regulatory documentation system ensuring radiation protection observance of workers and the public, including radiationhygienic criteria and standards of rehabilitation of contaminated territories.

In order to obtain comprehensive information with respect to current radiation circumstances at STS (independent from regulatory point of view), radiationhygienic monitoring of STS facilities has been carried out.

\section{Material and methods}

Over 2005-2008, more than 180 samples of environmental media, local foods and drinking water were collected in Andreeva Bay and Gremikha village expeditions; moreover, personal dose monitoring was implemented. Gammaspectrometry and radiochemical methods were applied in sample measurements.

\section{Characterization of SevRAO facilities in Andreeva Bay and Gremikha}

The STS Andreeva Bay is located on Kola Peninsula in the Barents Sea coastal strip (Motovsky gulf, west bank of Zapadnaya Litsa bay). The nearby settlements are: Bolshaya Lopatka $(2.4 \mathrm{~km})$; Nerpitchie village $(1.8 \mathrm{~km})$; Zaozersk city $(8 \mathrm{~km})$. The population is 15700 , the majority of which are military estates. The facility holds about $1.3 \cdot 10^{17} \mathrm{~Bq}$ of SNF and $6,0 \cdot 10^{14} \mathrm{~Bq}$ of RW, fig. 1 . 


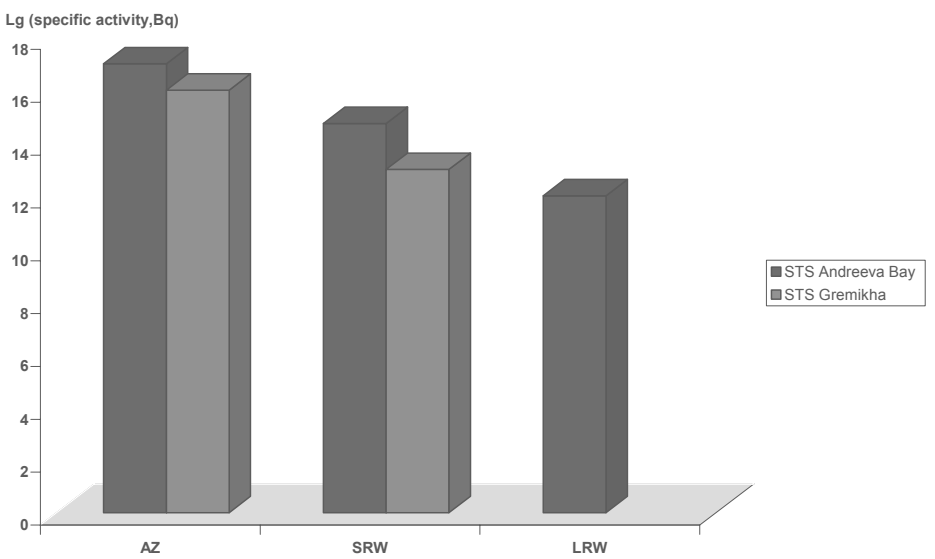

Figure 1: The total activities on STS of SNF and RW at Andreeva Bay and at Gremikha village (AZ - core (active zone), SRW - solid radioactive waste, LRW - liquid radioactive waste).

The STS Gremikha is located on Kola Peninsula in Chervyanaya Bay of the Barents Sea. The nearby settlements are: Gremikha village $(0.7 \mathrm{~km}$ from the site $)$ and Ostrovnoy city $(1.2 \mathrm{~km})$. The population is 3500 (mainly, former soldieries and their families). The facility holds about $1.3 \cdot 10^{16} \mathrm{~Bq}$ of SNF and about $3.3 \cdot 10^{13} \mathrm{~Bq}$ of $\mathrm{RW}$, fig. 1 .

Up to now, a large amount of SNF contained in 88 unloaded cores, as well as 17558 tons of solid radioactive wastes and 3042 tons of liquid radioactive wastes have been accumulated in Andreeva Bay and Gremikha.

\section{Specification of areas within the STS territory}

With the purpose of radiation protection of workers and the public, the following areas are specified on-site and around the STS site (see under the STS plan), fig. 2:

- Controlled access area (CAA-1) - SNF and RW store facilities are situated here and radiation-hazardous operations are performed here too;

- Uncontrolled (free access) area (UA-2) - Facilities intended for work supplying in CAA;

- Health protection zone (HPZ-3) - This is an area of administrative and technical provision of the STS;

- Supervised area (SA-4) - This is an area surrounding the STS, where radiological monitoring is carried out to guarantee radiation safety and protection for the public

The member of the public must not stay within the first three areas. 


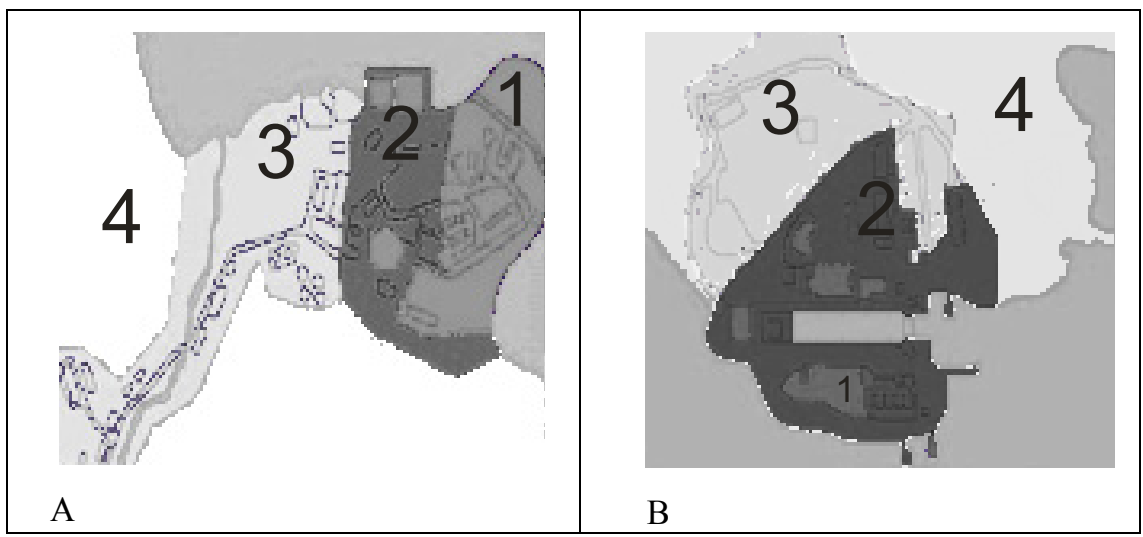

Figure 2: $\quad$ Plan A for STS location in Andreeva Bay Plan B for STS location in Gremikha.

\section{Radiation situation on-site the STS in Andreeva Bay}

The accomplished examinations showed that gamma dose rates within the STS territory varied over a wide range: in Control Access Area (CAA) - from 0.2 to $140 \mu \mathrm{Sv} / \mathrm{h}$; in Uncontrolled Area (UA) - from $0.2 \cdot 10^{3}$ to $12 \cdot 10^{3} \mathrm{~Bq} / \mathrm{kg}$ in Health Protection Zone (HPZ) - from $0.1 \cdot 10^{3}$ to $0.2 \cdot 10^{3} \mathrm{~Bq} / \mathrm{kg}$. Within Supervised Area (SA), gamma dose rates varies from 0.063 to $0.14 \mu \mathrm{Sv} / \mathrm{h}$ with an average value of $0.12 \mu \mathrm{Sv} / \mathrm{h}$, which does not differ from the levels typical for the territories of Northwest Russia and in the Murmansk region, in particular. The results of selective personal dose monitoring show that external exposure gamma rates of the public and workers of group B (individuals who are not working directly with the sources of ionizing radiation, but who, due to their working place location, can be exposed to radiation) due to natural and man-made sources of ionizing radiation are, respectively, equal to 0.8 and $0.9 \mathrm{mSv} / \mathrm{y}$. Internal public radiation doses associated with intake of radionuclides with food are $14 \mu \mathrm{Sv} / \mathrm{y}$. The total effective radiation doses to the public living in the STSs SA of Andreeva Bay (due to natural and man-made radionuclides) are estimated to be approximately $0.8-0.9 \mathrm{mSv} / \mathrm{y}$, that is not more than the actual norms.

The highest level radioactive contamination of soil on-site induced by manmade radionuclides is observed in the area of the old technological pier and around some SNF store facilities, where ${ }^{137} \mathrm{Cs}$ specific activity reaches $5.710^{7}$ $\mathrm{Bq} / \mathrm{kg}$, and that of ${ }^{90} \mathrm{Sr}$ is $5.710^{6} \mathrm{~Bq} / \mathrm{kg} .{ }^{137} \mathrm{Cs}$ and ${ }^{90} \mathrm{Sr}$ concentrations in soil within HPZ and SA is at the background level typical for "clean" Russian Northern areas and does not exceed $36 \mathrm{~Bq} / \mathrm{kg}$ and $4 \mathrm{~Bq} / \mathrm{kg}$, respectively (fig. 3).

\section{Radiation situation on-site the STS in Gremikha}

Gamma dose rate within CAA varies from 0.2 to $500 \mu \mathrm{Sv} / \mathrm{h}$ (maximum values are 4 times more than those in Andreeva bay); in UA - from 0.2 to $12 \mu \mathrm{Sv} / \mathrm{h}$ and 
levels within approximately $80 \%$ of the territory do not exceed $5 \mu \mathrm{Sv} / \mathrm{h}$. In HPZ and SA (in Ostrovnoy and Gremikha) it varies from 0.09 to $0.2 \mu \mathrm{Sv} / \mathrm{h}$, i.e., within fluctuation limits of natural background of this region. The results of selective personal monitoring of the people living and working (workers group B) due to natural and man-made sources of ionizing radiation in the STS area show that the external exposure gamma dose rates are $0.7 \mathrm{mSv} /$ year (for public) and $0.9 \mathrm{mSv} / \mathrm{y}$ (for worker group B). Internal public radiation doses due to intake of ${ }^{137} \mathrm{Cs}$ and ${ }^{90} \mathrm{Sr}$ with food are approximately $14 \mu \mathrm{Sv} / \mathrm{y}$, which is significantly lower than acceptable levels.

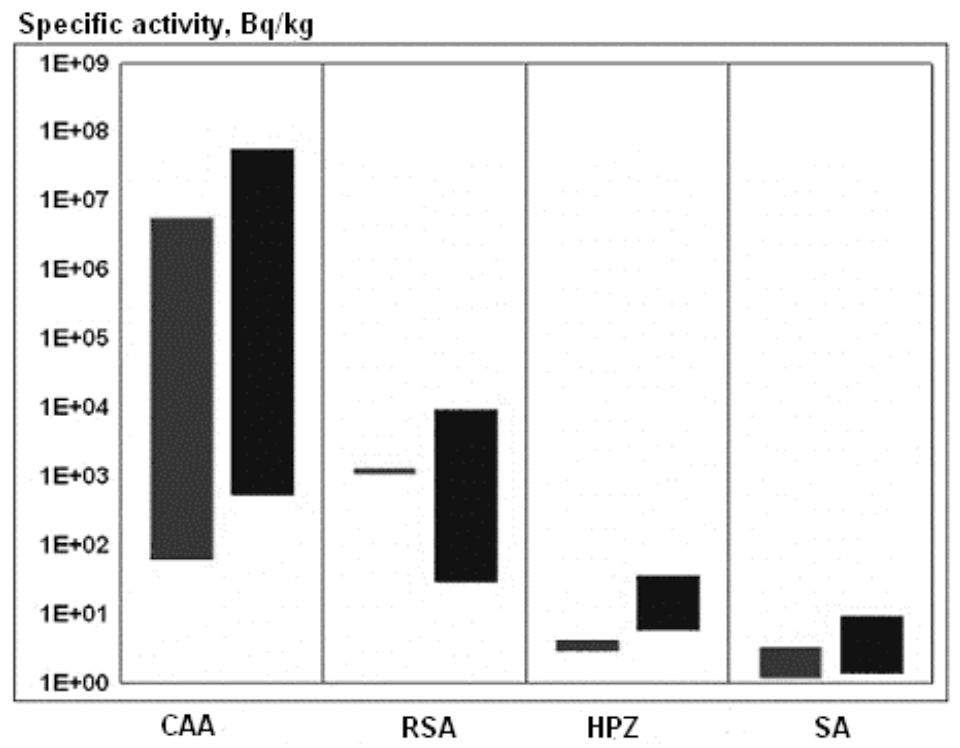

Figure 3: $\quad{ }^{90} \mathrm{Sr}$ (shown in light grey) and ${ }^{\mathbf{1 3 7}} \mathbf{C s}$ (shown in dark grey) contents in soil on STS in Andreeva Bay.

Within the industrial site, man-made contamination is observed in topsoil due to ${ }^{137} \mathrm{Cs},{ }^{90} \mathrm{Sr}$ and, in small concentrations, ${ }^{60} \mathrm{Co},{ }^{152} \mathrm{Eu}$, and ${ }^{154} \mathrm{Eu}$. In SA (including Gremikha and Ostrovnoy), ${ }^{137} \mathrm{Cs}$ and ${ }^{90} \mathrm{Sr}$ contents in soil are mainly within background level $(1-50 \mathrm{~Bq} / \mathrm{kg})$. In some cases, at local parts outside the settlements, observed levels exceed background values by up to $100 \mathrm{~Bq} / \mathrm{kg}$ by ${ }^{137}$ Cs (fig. 4).

\section{Results of radiation situation assessment at STS in Andreeva bay and Gremikha}

Radiation monitoring of the environmental media showed considerable exceeding of typical background values of ${ }^{137} \mathrm{Cs}$ and ${ }^{90} \mathrm{Sr}$ radionuclide concentrations (in the HPZ coastal strip) in seaweeds, bottom sediments and 
vegetation. An exceeding is also observed in some cases in the STS SA environmental media in comparison with background values. Preliminary results of sorption experiments of radionuclides on local soil and ground waters suggest that radionuclide migration from highly contaminated areas on site, via groundwater flow pathways, is possible. This leads to permanent entry of radioactive substances into the offshore marine environment.

According to radiation monitoring of catches in the STS off-shore marine environment, the concentration of ${ }^{90} \mathrm{Sr}$ and ${ }^{137} \mathrm{Cs}$ in fish is in the range 0.7$13 \mathrm{~Bq} / \mathrm{kg}$ for ${ }^{90} \mathrm{Sr}$ and $0.4-35 \mathrm{~Bq} / \mathrm{kg}$ for ${ }^{137} \mathrm{Cs}$, respectively, being significantly lower than actual Russian accepted radiation contamination levels. With the purpose of radiation exposure restriction during large-scale STS remedial work, FMBA established a public radiation dose quota; this quota is $100 \mu \mathrm{Sv} / \mathrm{y}$ due to effluents and $30 \mu \mathrm{Sv} / \mathrm{y}$ due to radioactive substance discharges (table 1).

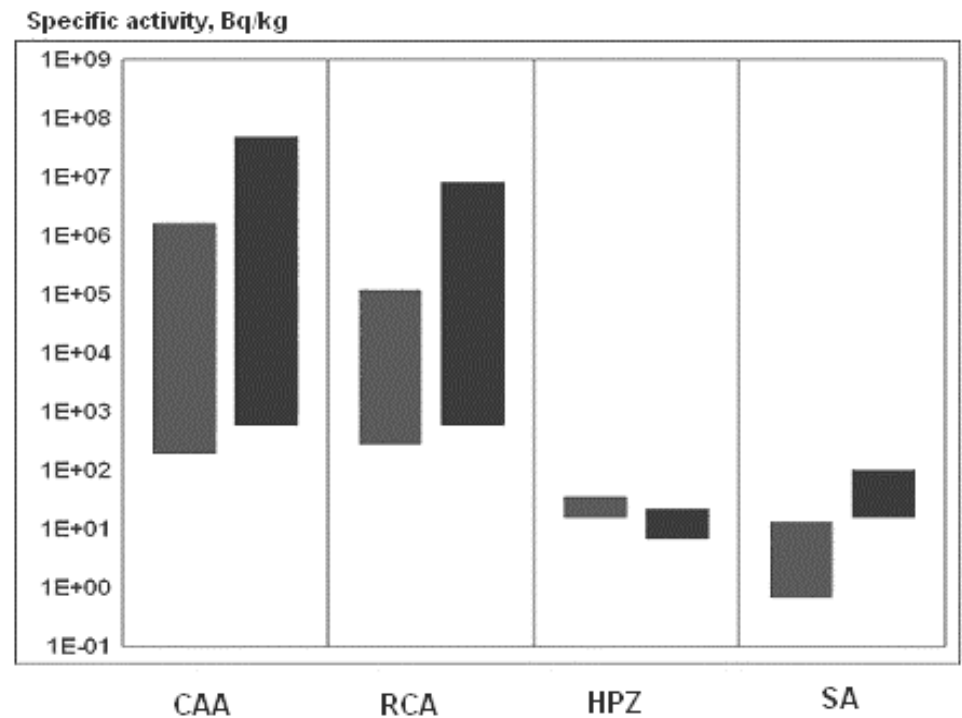

Figure 4: $\quad{ }^{90} \mathrm{Sr}$ (shown in light grey) and ${ }^{\mathbf{1 3 7}} \mathrm{Cs}$ (shown in dark grey) contents in soil on STS in Gremikha.

Table 1: $\quad$ Public radiation dose quota due to effluents and to radioactive substance discharges under conditions of STS facility normal operation.

\begin{tabular}{||l|c||}
\hline \hline Sources of exposure & Quota, $\mu \mathrm{Sv} / \mathrm{y}$ \\
\hline \hline Gas-aerosol discharges & 100 \\
\hline Intake with seafood & 30 \\
\hline Reserve for unregistered sources & 20 \\
\hline
\end{tabular}




\section{Conclusion}

Environmental radiation monitoring demonstrated significant excess (in comparison with typical background values) of ${ }^{137} \mathrm{Cs}$ and ${ }^{90} \mathrm{Sr}$ contents at local parts of the coastal strip of the STS health protection zone in seawater, seaweeds, bottom sediments, vegetation and soil.

Results of radionuclide sorption examination in soil and ground water permit to assume the presence of effective migration from contaminated areas via groundwater, causing radioactive inflow into offshore marine waters. Having in mind a possibility of further contamination of the STS area, dynamic surveillance is needed of the radiation situation both at routine activity, and at SNF and RW removal [2].

The described work carried out under joint FMBA and NRPA Project, devoted to regulation of the public radiation and nuclear safety during STSs operations, current output has included the following documents:

- InitialThreat Assessment for the situation at STS sites.

- Guidance "Criteria and norms on remediation of STS sites and facilities contaminated with man-made radionuclides".

- Guidance "Hygienic requirements for personnel and public radiation safety guaranteeing at the stage of designing the work with SNF and RW at STSs"

\section{References}

[1] Ilyin L., Kochetkov O., Simakov A, Shandala N, Savkin M, Sneve M, Borretzen P, Jaworskay A, Smith G, Barraclough I And Kruse P. "Initial Threat Assessment. Radiological Risks Associated with SevRAO Facilities Falling Within the Regulatory Supervision Responsibilities of FMBA". StrålevernRapport 2005:17. Østerås: Statens strålevern, (2005).

[2] Shandala N., Sneve M., Novikova N., et al. "Regulatory supervision of sites for spent fuel and radioactive waste storage in the Russian Northwest//J. Radiation protection.28 (2008), 453-465. 